\title{
Evaluation of implementation of the primary, secondary and tertiary prevention measures of the Surveillance Program of Gestational and Congenital Toxoplasmosis in the city of Londrina-PR
}

Aline Paschoal ${ }^{1}$, Juliana Bernardes ${ }^{2}$, Andre $\mathrm{Nadal}^{2}$, Juliana Boas ${ }^{2}$, Ana Silva ${ }^{2}$, Thais Cabral $^{2}$, Eloiza Caldart ${ }^{2}$, Fernanda Pinto-Ferreira ${ }^{1}$, Jaqueline Capobiango ${ }^{2}$, Italmar $^{2}$

Navarro $^{1}$, and Regina Mitsuka-Breganó ${ }^{2}$

${ }^{1}$ Universidade Estadual de Londrina

${ }^{2}$ Affiliation not available

January 27, 2021

\begin{abstract}
Objectives: evaluate the Surveillance Program of Gestational and Congenital Toxoplasmosis. Methods: 424 pregnant women were interviewed regarding their knowledge of prevention measures in 2019. Secondary prevention measures were assessed on the results of anti-Toxoplasma gondii serological tests were collected from pregnant women, from 2015 to 2018 . the tertiary prevention measures, we screened the babies of mothers who had recent suspected infections of $\mathrm{T}$. gondii to verify the referrals to the reference service. Results: $45.5 \%$ (192/424) reported that they had received guidance from health professionals; $35.4 \%$ $(68 / 192)$ changed their risk habits. The variables of schooling and age, having received prior guidance from health professionals and feline possession, proved to be significant when associated with the notions of preventive measures. 90.2\% (17,423 / 19,319) of pregnant women had undergone serological tests to detect anti- $\mathrm{T}$. gondii antibodies but there was an excess in requests for tests and medication and only $40.6 \%(26 / 64)$ of the children were referred to the referral hospital. Conclusions: the Program presents positive results regarding the performance of serological screening in prenatal care; however, the dissemination of knowledge about the prevention of toxoplasmosis and the request for tests need to be improved.
\end{abstract}

\section{Hosted file}

text file.pdf available at https://authorea.com/users/392089/articles/506114-evaluationof-implementation-of-the-primary-secondary-and-tertiary-prevention-measures-of-thesurveillance-program-of-gestational-and-congenital-toxoplasmosis-in-the-city-oflondrina-pr 

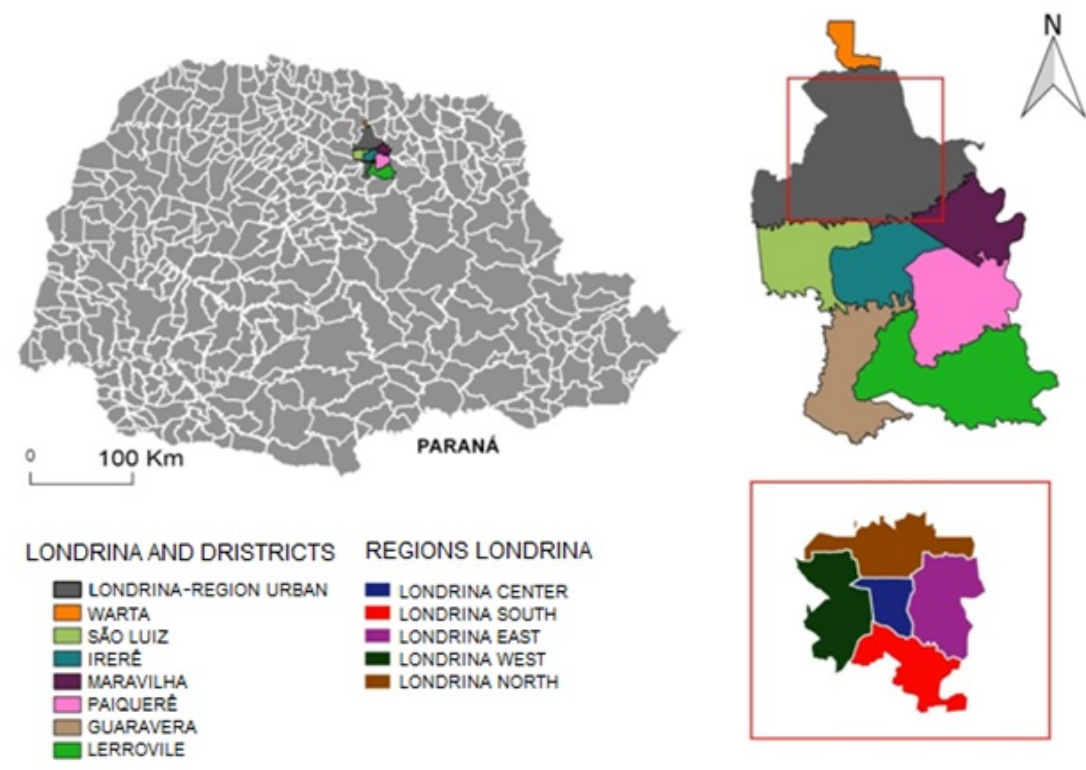


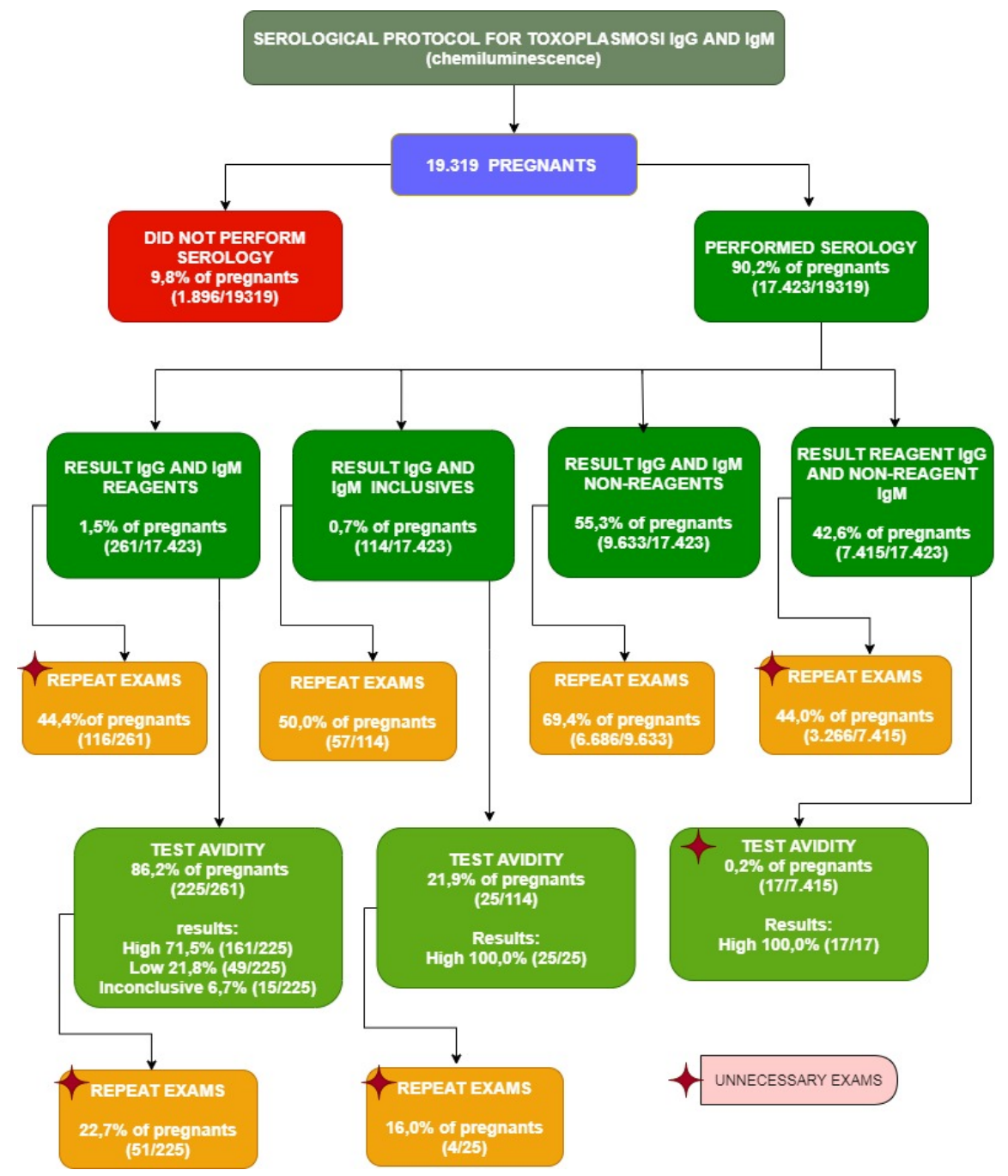




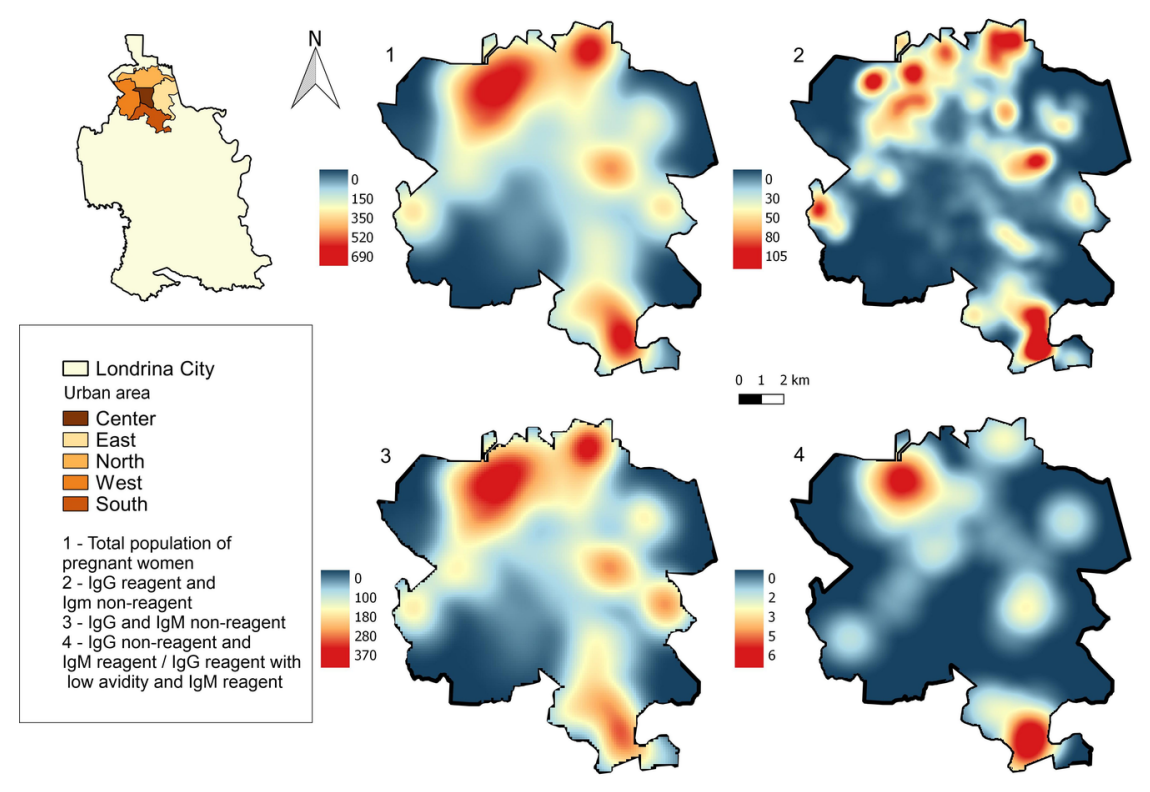

